\title{
A Role for the Cytoskeleton in Heart Looping
}

\author{
Kersti K. Linask ${ }^{1, *}$ and Michael VanAuker ${ }^{2}$ \\ University of South Florida (USF) and All Children's Hospital (ACH), ${ }^{1}$ Department of \\ Pediatrics, The Children's Research Institute, St. Petersburg, FL 33701 and ${ }^{2}$ USF- \\ Department of Chemical Engineering, Tampa, FL 33620 \\ E-mail: klinask@health.usf.edu; vanauker@eng.usf.edu
}

Received October 31, 2006; Revised January 17, 2007; Accepted January 23, 2007; Published February 19, 2007

Over the past 10 years, key genes involved in specification of left-right laterality pathways in the embryo have been defined. The read-out for misexpression of laterality genes is usually the direction of heart looping. The question of how dextral looping direction occurred mechanistically and how the heart tube bends remains unknown. It is becoming clear from our experiments and those of others that left-right differences in cell proliferation in the second heart field (anterior heart field) drives the dextral direction. Evidence is accumulating that the cytoskeleton is at the center of laterality, and the bending and rotational forces associated with heart looping. If laterality pathways are modulated upstream, the cytoskeleton, including nonmuscle myosin II (NMHC-II), is altered downstream within the cardiomyocytes, leading to looping abnormalities. The cytoskeleton is associated with important mechanosensing and signaling pathways in cell biology and development. The initiation of blood flow during the looping period and the inherent stresses associated with increasing volumes of blood flowing into the heart may help to potentiate the process. In recent years, the steps involved in this central and complex process of heart development that is the basis of numerous congenital heart defects are being unraveled.

KEYWORDS: heart looping, cardiac, nonmuscle myosin II, flectin, cytoskeleton, actin, biomechanics, blood flow, shear stress, integrin, microcilia, extracellular matrix

\section{INTRODUCTION}

Heart looping is a central process in cardiac development. Looping in all vertebrates that have been analyzed begins with a rightward movement of the anterior part of the developing straight heart tube. At this period, the ventricular area of the heart is cephalad to the atrial region. Blood flow into the straight heart tube is initiated concomitant with initiation of myocardial contractions and of looping. Looping is completed with the positioning of the atria anterior to the ventricles and dorsal to the outflow tract. Only after completion of looping does the four-chambered heart form. Subsequent heart development involves formation of the septa and valves, thus leading to parallel blood flow through the heart. Changes in gene expression or protein interactions that are involved in this complex process have serious consequences for 
subsequent heart development. It is thought that many cardiac anomalies associated with congenital heart disease arise with this process.

\section{LATERALITY AND DIRECTIONALITY OF CARDIAC LOOPING}

The heart is the first organ to break left-right symmetry in the embryo by looping in a rightward, or dextral, direction. Therefore, cardiac looping direction has been widely used as an experimental read-out for defining genes that specify laterality in the embryo[1,2,3,4,5,6]. Many complex human congenital heart defects occur when genes associated with laterality specification in the embryo have mutated or been deleted[7]. Although the heart may be the first organ to break left-right axis symmetry, an earlier process associated with establishment of laterality was shown to involve nodal flow that is autonomously generated by the leftward movement of cilia in a 9+0 configuration that are tilted caudad on cells of the ventral node[8,9,10,11]. Recent evidence suggests that the leftward movement of membrane-sheathed particles is associated with the activation of the noncanonical Hedgehog signaling pathway and results in an asymmetric elevation of intracellular $\mathrm{Ca}^{++}$, together with changes in gene expression[8,12,13,14]. Nodal flow, however, is not conserved in vertebrates and it may not be the only mechanism that breaks asymmetry in the mouse. For example, we observed an asymmetric expression of the sodium-calcium exchanger NCX-1 protein with greater expression apparent in the right side of Hensen's Node than on the left[15]. It was suggested that calcium signaling, as based on the asymmetric NCX localization in the Hensen's Node, similar to that of connexin 43[16], may affect laterality[15]. In the frog and avian embryo, ion channels and gap junction communication have been shown to have roles in establishment of asymmetry[17]. Downstream from the nodal flow/gap junction/NCX-1 asymmetry is the activation of Nodal gene expression. Nodal expression in vertebrates was usually reported as localizing only in the left lateral plate mesoderm (LPM) and not in the right. Recent experimental data using RT-PCR and mathematical modeling indicate, however, that Nodal expression is seemingly initiated in the right LPM by an activating signal. Right LPM Nodal expression is then rapidly down-regulated by inhibition from the midline, and remains expressed in the left LPM by what the authors term a "self-enhancement and lateral-inhibition" system (SELI)[18]. The resulting left LPM Nodal expression precedes visible heart looping or axial rotation of the embryo. It remains expressed until approximately the 12-14 somite stage[19,20]. Downstream of Nodal is Pitx2, a homeobox gene that is the only laterality gene shown so far to be expressed within the left wall of the straight heart tube and not in the right. Deletion or inactivation of Pitx2 has been correlated with defects in heart morphogenesis: The observed developmental anomalies include valve defects, sinoatrial anomalies, and alignment problems, as characterized by double outlet right ventricle and transposition of the great arteries, as well as right ventricle hypoplasia[21,22,23]. It should be noted that Pitx2 null mice had correct, dextral looping of the heart. Our misexpression studies of Pitx2c and CFC in the chick heart fields provided evidence that expression of a specific threshold concentration of flectin, a novel myocardial-associated protein in the left or right chick embryonic heart, was the best indicator of the direction and rotation of heart looping[24,25,26,27]. Other reports on the importance of threshold levels of Pitx2 activity in the mouse[22] supported this conclusion.

\section{THE SECOND HEART FIELD AND A ROLE FOR THE DORSAL MESOCARDIUM IN HEART LOOPING}

The heart tube during looping includes the following segments in anterior to posterior order: the developing outflow tract and part of the right ventricle that are emerging from the anterior heart field, the left ventricle that has formed from the first cardiac lineage and displays a C-loop at this time, and the right and left atria forming at the same posterior level from the posterior heart field[28]. Thus, looping occurs concomitantly with an increase in length of the primary or primitive heart tube with new segments being added from the 
second, anterior and posterior, heart fields. Anteriorly, the formation of the outflow tract occurs by asymmetric cell proliferation. There are more mitotic cells in the left dorsal mesocardial fold, and in the ventral floor of the foregut than in the right fold[29] (Fig. 1). We suggested that it is this asymmetric, leftdominant, cell proliferation pattern that drives the dextral directionality of looping. Experimental evidence
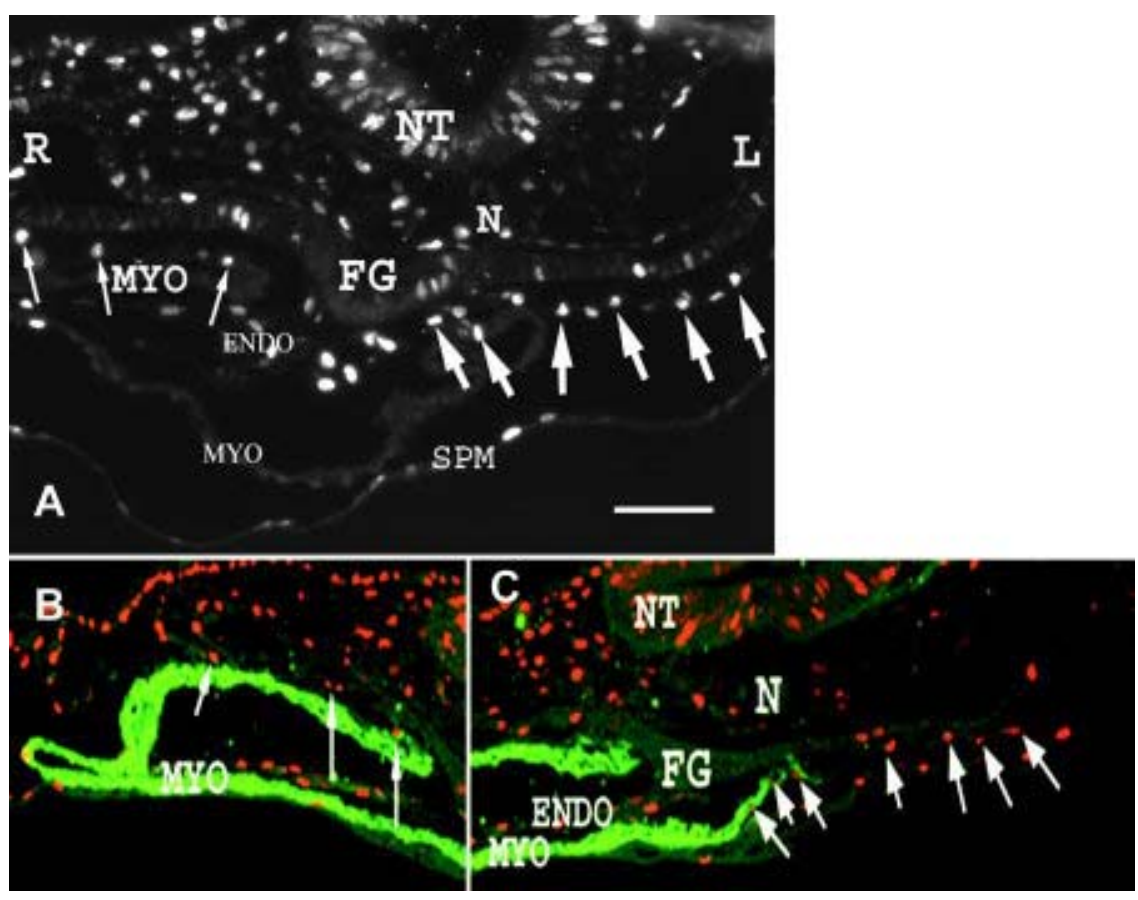

FIGURE 1. Asymmetric cell proliferation is evident in the dorsal mesocardial (DM) folds that are emerging from the anterior heart field. BrdU-labeling (arrows) shows that more cells are undergoing mitosis in the left DM fold (larger arrows) than in the right (smaller arrows) to initiate rightward directionality of looping between 7-9 somite stages. Reproduced with permission from Linask et al.[29].

indicates that the dextral direction, as based on signaling associated with asymmetric cell proliferation patterning in the chick, occurs between the 7-9 somite stage, i.e., early HH stage 9[29]. Posteriorly, the right and left atrial segments are forming by addition of cells to the primary heart tube in a symmetric manner. As cells arise from the second lineage contributing to the length of the heart tube[28], the dorsal mesocardial (DM) folds also form from the anterior field. The DM folds continue to display asymmetric cell proliferation[29]. The left and right DM folds approach each other from the lateral regions, merge, and then constrict at the embryonic midline. The dorsal mesocardium maintains the position of the heart relative to the midline of the ventral floor of the foregut. As looping proceeds, the elongating heart tube deepens its rightward bend.

In order for the heart tube to continue bending or looping, it must be released from its DM attachment along most of the heart tube. The DM attachment undergoes relatively rapid degradation by matrix metalloproteinase (MMP) activity, first apparent at the mid-level of the heart tube. The breakdown by MMP-2 activity continues anteriorly and posteriorly until the heart remains attached posteriorly only at the anterior intestinal portal. This posterior attachment site becomes the permanent DM (PDM) attachment area at the midline of the embryo[29]. The PDM is characterized by being rich in several extracellular matrix (ECM) proteins and is seemingly protected from proteolytic breakdown, as no MMP2 mRNA is detected at this site. Apoptosis is not involved in the dissolution of the dorsal mesocardium and the breakdown occurs by degradation of the ECM[29]. It is only after the breakdown of the rest of the dorsal mesocardium that heart tube looping can be completed. It is noteworthy that MMP-2 activity is 
involved in coordinating several aspects of heart morphogenesis: first, the fusion of the right and left cardiac epithelial compartments to form a tube; subsequently, in directionality of looping through effects on asymmetric cell proliferation; and finally, enabling the completion of looping with the breakdown of the dorsal mesocardium. Mechanisms of MMP-2's role may relate to activation of factors at the membrane or the release of growth factors or growth factor-like domains from the ECM that can then bind to cell surface receptors. The precise definition of the MMP mechanism remains among areas for future investigation.

\section{THE UNDERLYING CELLULAR MECHANISMS OF HEART LOOPING}

The shaping of tissues during organ development requires cell migrations, cell shape changes, and bending of epithelial sheets to form tubular structures that, in turn, undergo subsequent morphogenetic movements until the final shape of the organ is achieved[30,31]. These described morphogenetic changes all occur within the context of early heart development. Mesenchymal precardiac cells migrate from the anterior regions of the primitive streak into the bilateral heart fields[32,33]. The precardiac mesenchymal cells migrate anteriorly and toward the midline over a fibronectin substratum[34,35,36,37,38] where they sort out via $\mathrm{N}$-cadherin/ $\beta$-catenin-mediated adhesion to form two ventral, epithelial compartments[30,39,40]. The epithelial compartments bend ventrally and undergo ventral closure to form a straight heart tube[29,41]. The anterior-posterior and dorsal-ventral patterning of cell-cell and cellmatrix adhesion molecules and their activity in signal transduction pathways are keys to driving the threedimensional form of the organ, as well as cell differentiation. It is now becoming generally appreciated that the cross-talk between these adhesion signaling pathways associated with cell differentiation and heart morphogenesis involves outside-in and inside-out signaling via the cytoskeleton (Fig. 2).

The information on the underlying molecular mechanisms of the bending and rotational component of looping remains very limited. From analyses of invertebrate models, it appears that the unconventional myosins in association with the actin cytoskeleton has a central role in left-right determination[42], and we suggest that the actomyosin cytoskeleton also have a central role in vertebrate heart looping. Cytoskeletal restructuring is required for cell shape changes, for the movement of cells, and for the shaping of tissues throughout morphogenesis. Cells depend on cytoskeletal molecules and molecular motors to establish their asymmetrical shapes, to transport intracellular constituents, and to facilitate cell motility. The assembly of the cytoskeletal components and action of the associated motors is largely responsible for establishing cellular architecture and tissue structure[43].

The bending forces within the heart tube appear to have a common underpinning related to tension and contractility of the cytoskeleton. Prior and recent studies have indicated actin to be a major component of looping[44,45,46,47]. Confocal laser scanning microscopy reveals that development and organization of actin filaments considerably differ in inner and outer myocardial cell layers[48]. Myocytes in the outer layer facing the pericardial cavity are round. In the inner layer, myofibrils localize at the bottom, facing the cardiac jelly. At the tubular heart stage when the tube begins to bend, F-actin is aligned with its long axis coinciding circumferentially in relation to the tubular structure (diagrammatically shown in Fig. 2), as also can be seen in this embryonic chick heart immunostained for actin localization and prepared for three-dimensional analyses (Fig. 3). It was suggested that these circumferentially arranged actin filaments at the base of the inner layer of the myocardium are important for promoting cardiac looping[48,49]. Fibronectin (FN) is aligned parallel with the actin bundles early in looping, but during looping, FN becomes more fragmented and appears in a speckled pattern[50]. We observed the speckled FN localization during looping as well[27]. This may relate to MMP-2 activity that we observed to be an important component of looping[29]. A member of a the $\mathrm{Ca}++$-dependent family of adhesion molecules, N-cadherin, is responsible for the connection of actin and myofibrils between neighboring myoctes at cell-cell junctions[39,51,52], and for the cell alignment and arrangement of the two layers of the developing heart tube[53]. Loss of N-cadherin leads to alterations in connexins, possibly via changes in cytoskeletal signaling[54]. Additionally, it has been shown that N-cadherin is involved in 
the oriented responses of cardiomyocytes induced by mechanical stretch in vitro[55]. Thus, during looping, as in the earlier period of cardiac compartment formation, cross-talk between two mechanosensing and adhesion mediated-signaling pathways, integrin and $\mathrm{N}$-cadherin, is evident[56]. The cross-talk appears to be facilitated by the cytoskeletal molecules as NMHC-II proteins and actin (see below), among others.
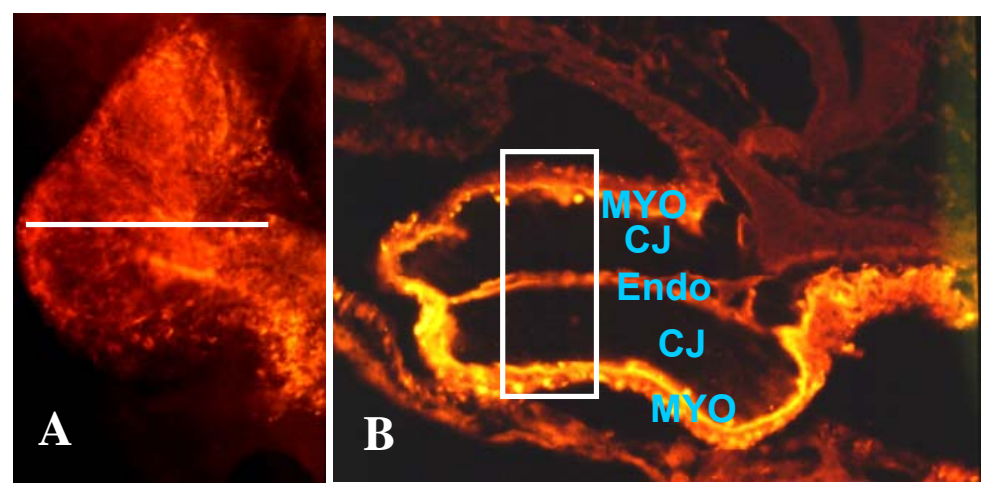

$A$ and $B$

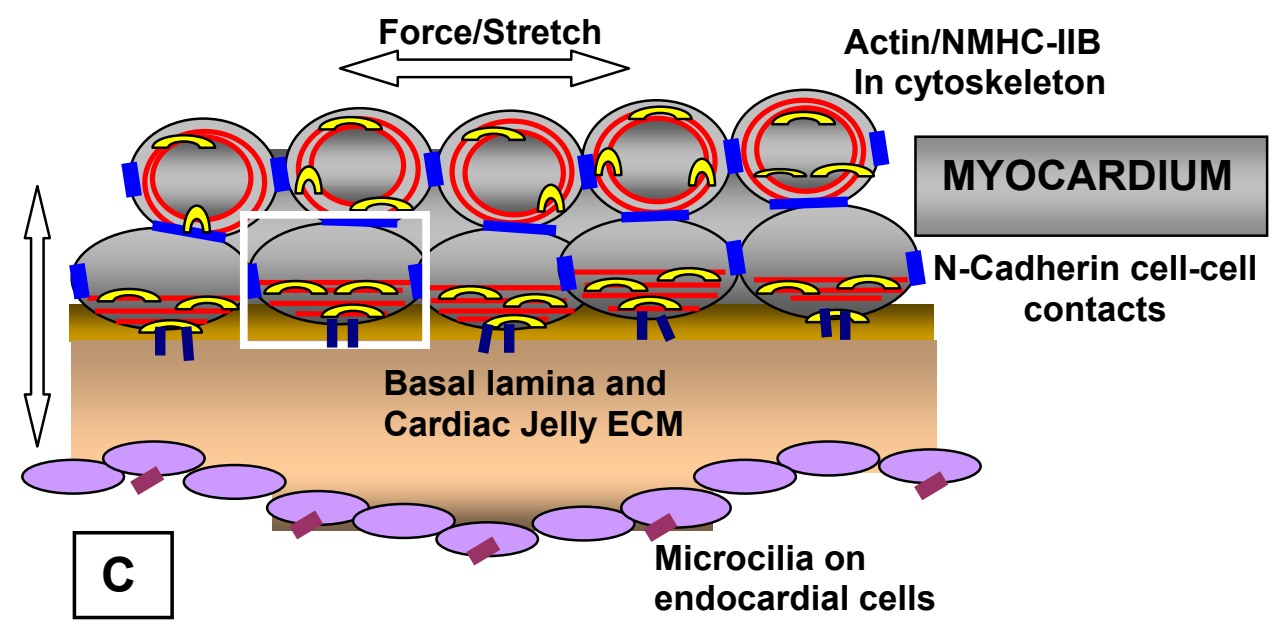

C

FIGURE 2. A hypothetical model based on current literature shows the cytoskeleton at the "hub" of cross-talk between cell-to-cell and cell-tomatrix interactions that are involved via signaling pathways in coordinating development of cardiac form and function. Accumulating evidence suggests that the cytoskeletal signaling involves interactions between the nonmuscle myosin II (NMHC-II) class of motor proteins and actin. Fig. $2 \mathrm{~A}$ depicts a looping stage 11 chick heart immunostained for flectin. Section (plane of section depicted by white line) through the heart is shown in panel 2B showing the relationship (see boxed in region) of the myocardial (Myo) wall, basal lamina/cardiac jelly (CJ), and endocardium (Endo). Fig. 2C shows a diagram of a general model depicting the organization of the actin[48] (red fibers) and nonmuscle myosin (yellow arcs) in the inner and outer layer of the two-layered myocardium during the looping stages 11/12 in the chick heart. Basal lamina and cardiac jelly are shown, as well as the monociliated endocardial cells that are able to detect shear stresses of blood flow. Block arrows depict stretch and force on the cardiac cells. 


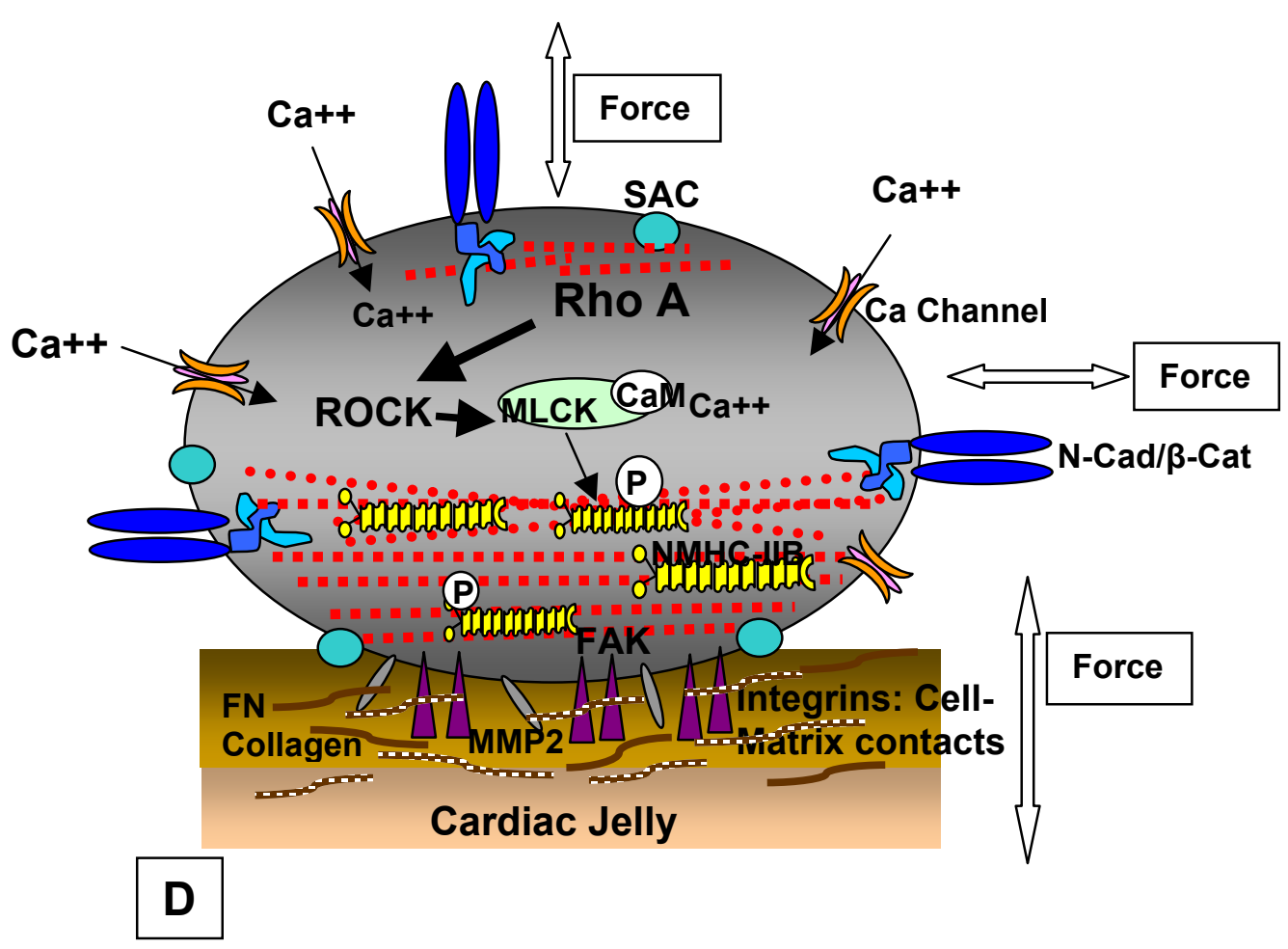

FIGURE 2D

FIGURE 2 cont. Panel 2D, depicts the subcellular cytoskeletal-mediated mechanisms in the inner myocardial wall by which focal adhesion kinase (FAK) at the basal side mediates integrin-, and its role in cyclic stretch, signaling in association with the cytoskeleton. Small cardiomyocyte cell processes are shown extending into the basal lamina (see also Fig. 6). MMP-2 is thought to interact within the ECM in the microenvironment to release activating factors that can bind to cell surface receptors, as well as lead to ECM degradation. N-cadherin/ $\beta$ catenin complex functions in association with connexins and regulates cyclic stretch by its interactions with the cytoskeleton, as well as neighboring cells through mediation of cell-cell adhesion. Rho proteins, ROCK, $\mathrm{Ca}++/$ calmodulin $(\mathrm{CaM})$, regulate force through phosphorylation of nonmuscle myosin light chain via myosin light chain kinase (MLCK), as well as phophorylation of other cytoskeletal proteins. In addition to the depicted calcium channels shown are stretch activated channels (SAC) that are known to be expressed in the embryonic chick heart[119]. Cation selective $(\mathrm{Ca}++$ and $\mathrm{Ba}++)$ SACs can provide mechanosensitivity when a cell is mechanically stimulated and are proposed to be anchored to the cortical cytoskeleton and possibly to the ECM[120]. 

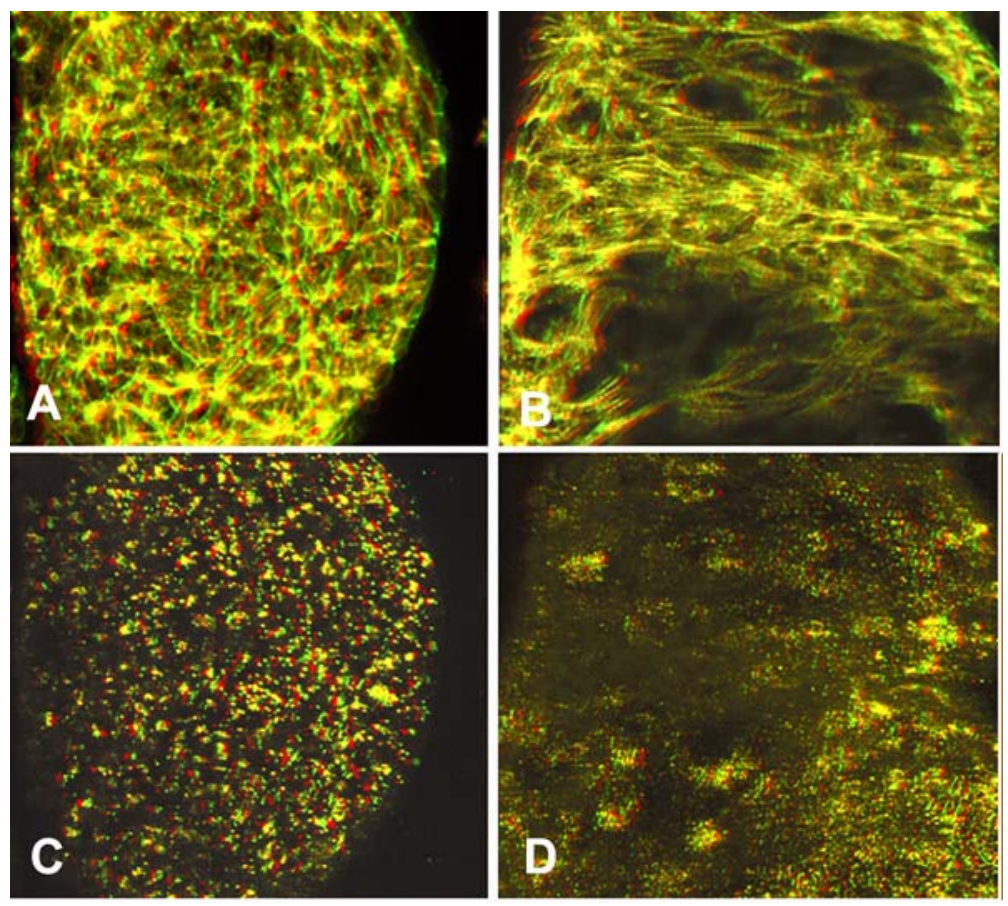

FIGURE 3. Three-dimensional confocal rendering of organization of F-actin (red, panels 3A, 3B) and flectin (green, panels 3C,3D) at HH stage 9 (Figs. 3A and C) and stage 11 chick heart (Figs. 3B and 3D). Readers will need red and green color glasses to visualize the 3D information. Between stages 9 and 11, F-actin in the myocardial layer near the cardiac jelly becomes circumferentially arranged around the heart tube during looping. More flectin is present in the left side of the avian heart tube in a punctate manner in relation to the myocardial layer and within the adjacent cardiac jelly.

\section{FLECTIN, NONMUSCLE MYOSIN II, AND LOOPING}

Flectin was the first protein shown to be expressed in a left-right manner in the myocardium of the heart[27]. Flectin was identified as F22, a $240 \mathrm{kD}$ protein [57,58]and was first described in relation to retinal pigment epithelial cells and the interphotoreceptor matrix (IPM) of the embryonic day 14 chick eye. It is an evolutionarily well-conserved protein[59]. The IPM is situated between the photoreceptors and the retinal pigment epithelium. It is involved in the development and maintenance of photoreceptors, and is a major factor in retinal adhesion[60]. Flectin is expressed asymmetrically in the myocardial wall of the mouse, as well as chick, embryonic tubular heart. There is dominant expression in the left heart wall and a lower level in the right. The dominant sidedness is modulated by laterality specifying genes. Regardless of the sidedness of Pitx 2 expression, it is the dominant sidedness of flectin expression that most closely correlates with the direction of looping: If there is more flectin expressed in the left dorsal mesocardium and myocardium, hearts loop normally to the right; if there is more in the right side, hearts loop abnormally to the left. If there is no flectin or equal amounts of flectin in the two sides, the straight tubular heart does not loop[24,25].

In a recent collaborative study using immunoprecipitation with flectin antibody of looping heart extracts, flectin was identified by MALDI-Mass Spectroscopy and proteomics as closely related to, associated with, or being a variant of the nonmuscle myosin II (NMHC-II) family of proteins[61]. The precise separation and definition of what appears to relate to the nonmuscle myosin II isoforms are currently being analyzed. As based on available published data, in itself the nonmuscle myosin II protein family appears a good candidate to be involved in looping. The expression pattern of NMHC-IIB in the mouse heart appears similar to flectin in that a left-dominant asymmetric expression occurs in the dorsal 
mesocardial region and myocardium (unpublished observation). In the chick NMHC-IIB was shown immunohistochemically to be associated with actin during myofibrillogenesis in the differentiating cardiomyocyte[62]. A unique NMHC-IIA-like isoform has been described for retinal pigment bovine epithelial cells that exists in association with stress fibers and also in membrane vesicles[63]. NMHC-II proteins are well situated to act in mechanotransduction of biomechanical forces that are associated with initiation and increase of blood flow and the resulting compressive forces exerted on the cardiac jelly during the initiation of heartbeats, as well as of tube bending and rotational forces. Notably nonmuscle myosin IIs are found in many systems associated with mechanotransduction, for example in microcilia of the inner ear and in cell processes associated with afferent and efferent kidney arterioles[64,65,66,67]. When mutated, hearing loss and hypertension can result.

In early reports[26,27] we reported flectin as being only an asymmetrically expressed extracellular matrix (ECM) molecule due to its localization in the cardiac jelly, an extensive acellular region prevalent during the heart looping stages that is situated between the myocardium and endocardium. However, after degradation of the cardiac jelly using hyaluronidase, it was clear that flectin was present also intracellularly within the myocardium, and that it was modulated in the myocardial wall by upstream laterality genes[25,68]. It was, however, the dominant left-sidedness of flectin within the myocardial wall that most closely related to right heart looping. A role for the cardiac jelly ECM in looping can be questioned in general, because when the cardiac jelly is removed by hyaluronidase degradation of proteoglycans within this extracellular matrix compartment, both in the rat[69] or chick[68] embryos, the heart tube flattens, but continues to bend. It should be noted, however, that the glycoproteins within the myocardial basal lamina, as FN and collagen, most likely would remain localized, but was not analyzed in these experiments. Whether looping can be completed, remains to be established because the experiments were terminated too early. It has been claimed that the chick heart isolated in culture can still bend[70], also when blebbistatin that affects nonmuscle myosins is used to perturb cytoskeletal interactions[71]. However, the latter observation did not take into account that isolated tissues placed into culture tend to bend normally. It was not ruled out that the observed tissue "bending" may be due to a release of normal tensions on the myocardial tissue upon isolation. Importantly, in isolation the heart tube does not complete looping to form a four-chambered heart. We suggest that both normal fluid stresses and asymmetric forces within the myocardium are necessary to drive looping to completion.

Knockout mouse models for both NMHC-IIA and NMHC-IIB have been generated. The NMHC-IIA knockout embryo is an embryonic lethal already at ED 7.5, before a tubular heart forms[72]. In NMHC II-B knockout mice in which heart do develop, heart defects apparently associated with looping abnormalities are reported[73]. Approximately $65 \%$ of the NMHC-B-/- embryos died before birth, and those that were born had congestive heart failure and died during the first day after birth. Six of seven NMHC-IIB -/- newborn mice showed structural cardiac defects. These studies indicate that nonmuscle myosin II-B is required for normal cardiac development and that its absence results in structural defects associated with misalignment and in that in many respects, resemble two common human congenital heart anomalies, tetralogy of Fallot and double outlet right ventricle[73]. The absence of NMHC-IIB resulted in a significant increase in the transverse diameters of the cardiac myocytes. This may result in abnormal feedback of the developing myocardium, which in turn is unable to complete the cardiac looping process normally. There is a need to study the role(s) of NMHC-IIB, and its relationship with NMHC-IIA during heart tube formation and looping in still greater detail. In most systems where both nonmuscle myosins are expressed, the two NMHC-IIs have different roles within the same cell. Interestingly, nonmuscle myosin has been demonstrated as involved in promoting the retention of homeodomain transcription factors to the cytoplasm[74]. It would be of interest to determine whether a similar interaction occurs between Pitx2c and dominant- left sided NMHC-IIB expression in the heart. 


\section{RHOA AND INTEGRIN SIGNALING PATHWAYS INVOLVEMENT IN CARDIAC FORM AND FUNCTION}

In mammalian cells, Rho proteins regulate the formation of the actin cytoskeleton in stress fibers, lamellipodia, and filopodia and are downstream effectors of RhoA GTPase[75]. The Rho-associated kinase family is comprised of Rho kinase/ROCK2/ROK $\alpha$ and $\mathrm{p} 160 \mathrm{ROCK} / \mathrm{ROCK} 1 / \mathrm{ROK} \beta[76]$ and are all implicated in the regulation of cytoskeletal organization[77]. Rho kinase transcripts are expressed in the cardiac mesoderm, lateral plate mesoderm, and the neural plate [78]. A pyridine derivative, Y-27632, has been demonstrated to selectively inhibit 160 ROCK[79]. When HH stage 4-8 whole chick embryos or comparable staged mouse embryos are exposed in culture to Y-27632 (as well as antisense to p160 ROCK), precardiac cell migration, cardiac tube formation, and establishment of normal left-right asymmetry are disrupted[78]. In a subsequent study using a reverse genetic approach of cardiac-specific inhibition of Rho family protein, the transgenic embryos showed incomplete looping, lack of chamber demarcation, inhibition of cell proliferation, and lack of trabeculation [80] These described phenotypes of the chick and mouse are similar to those we reported with MMP-2 inhibition or with Pitx2 misexpression and changes in flectin expression[24,25,29]. In addition, Rho kinase via its pleckstrin domain apparently binds directly to NMHC-IIA and -IIB in in vitro cosedimentation assays[81]. Inhibition of RhoA/ROCK, using another inhibitor Simvastatin, negatively affects matrix metalloproteinase (MMP) secretion and reduces MMP mRNA levels[82]. We have also shown that MMP-2 is important in a temporal manner in cardiac tube formation, ventral closure, and looping[29]. Vascular endothelial cadherin signals through RhoA/ROCK to regulate cytoskeletal tension and focal adhesions[83]. Additionally, RhoA/ROCK signaling is important for focal adhesion kinase (FAK) activation at focal contacts in cardiomyocytes by cyclic stretch and by its relationship to the cytoskeleton[84]. Phosphorylation of NMHC-IIB regulatory light chain (MLC) regulates NMHC-II activity and this regulation occurs by distinct upstream signals, such as $\mathrm{Ca}++/$ calmodulin and the Rho family GTPases. Both signaling pathways are involved in cyclic stretch in cardiomyocytes by their interactions with NMHC-IIB in the cytoskeleton[84]; and Rhomediated pathway has been shown to perturb looping[78]. It has been shown also that in culture Pitx2a affects actin-myosin interactions through Rho GTPase signaling[85]. That Rho-kinase regulates tissue morphogenesis via nonmuscle myosin has also now been shown during Drosophila development[86]. A Type ID unconventional myosin appears to control left-right asymmetry in Drosophila through the adherens junction as it colocalizes with $\beta$-catenin[42]. These reports taken together, suggest that Rho kinase regulates early morphogenetic events associated with cardiac tube formation and looping by altering normal ECM- cell surface-cytoskeletal interactions at focal contacts, and also modulating NMHC-II/actin interactions. These aspects need to be addressed in future experiments in association with looping.

Of interest is that downstream Rho kinase activity affects FAK at focal contacts. These integrinbased focal contacts can act as mechanotransducers of forces associated with stretch as increasing volumes of blood entering the heart during the looping stages to relay information of compressive forces within the cardiac jelly to the myocardial wall. This possibility may relate to our finding that embryos exposed to RGD peptides that inhibit cell binding of extracellular matrix molecules, as fibronectin and collagen, to integrin receptors at focal adhesion sites[87,88], also exhibit randomization of cardiac leftright asymmetry[89]. Normal mechanotransduction signaling would expectedly also be disrupted.

When we analyzed the effects of RGD (GRGDNP; GibcoBRL) peptides on flectin localization in the chick heart during looping, we found a reduced and disorganized expression of flectin together with randomization of looping. In a concentration $(10 \mathrm{ug} / \mathrm{ml}$ to $100 \mu \mathrm{g} / \mathrm{ml})$ and stage (HH stage 5-8) dependent manner embryos exposed to RGD peptides displayed a down-regulation of flectin (FL) and fibronectin (FN) localization in the heart and basement membrane in the myocardium substratum in comparison to embryos that were treated with similar concentrations of RGA (GRADSP) or RGE (GRGESP) control peptides (Fig. 5). Generally the cardiac ECM matrix compartment was decreased in size with RGD peptide exposure. Chick embryos shown in fig. 5 were exposed to RGD peptides at stage 5/6 and incubated for $24 \mathrm{hrs}$. After the incubation period, embryos were fixed and doubly immunostained for 
flectin (FL) and fibronectin (FN). In Fig. $5 \mathrm{~A}$ and $\mathrm{B}$ embryos exposed to control peptides exhibit normal looping and an extended cardiac jelly compartment. In the RGD-peptide exposed embryos (panels 5C$5 \mathrm{H})$, the anterior heart regions show a relatively normal tubular structure and a high level of flectin in the myocardium (C) and fibronectin (D) at the basal side of the myocardial wall. Fibronectin is also prominent at the midline in association with the ventral floor of the foregut (see white line in D). Unlike in control embryos, little flectin is detectable in the cardiac jelly. After $24 \mathrm{hrs}$ of peptide exposure, the more undifferentiated posterior regions of the heart field at time of exposure, display a much-decreased ECM compartment in the developing heart regions and less flectin expression (panel E) within the cardiac compartments in comparison to fibonectin that generally remains expressed at relatively higher levels. Within the posterior heart areas (panels $5 \mathrm{E}-5 \mathrm{H}$ ), flectin becomes almost undetectable, while fibronectin remains expressed. These experiments show that flectin expression in the matrix/basement membrane is significantly decreased, when integrin receptor-mediated cell association with matrix molecules is inhibited. With RGD-exposure both heart development and normal looping are inhibited[87,89].

\section{NONMUSCLE MYOSIN II AND MECHANOTRANSDUCTION}

Myosin is a family of proteins that generates mechanical force by catalyzing hydrolysis of ATP when interacting with actin filaments. Across species more than 10 genes encode myosin heavy chains II. These are divided into two subclasses, the sarcomeric and the nonsarcomeric (smooth and nonmuscle), as based on homologies of primary sequences. In the human genome, there are three genes (MYH) for nonmuscle myosin II defined as NMHC-IIA (MYH9), NMHC-IIB (MYH10), and NMHC-IIC (MYH14). Class II myosins consist of a pair of heavy chains $(\sim 200 \mathrm{kDa})$ and two pairs of light chains $(15-20 \mathrm{kDa})$. Myosin II proteins have been demonstrated to have important functions in diverse cellular contractile and motile processes, including cell migration, muscle contraction, cell division, cell shape changes, cell adhesion, and extracellular matrix remodeling in eukaryotic cells. While a member of the nonmuscle myosin II protein may be present in all eukaryotic cells in higher organisms, they are differentially expressed and appear to have different functions. The functions of NMHC-II proteins appear well conserved across phyla; however, little is yet known about their diverse roles in vertebrate morphogenesis. Biochemical, genetic, and cell biological studies in Drosophila and Dictyostelium, have demonstrated that nonmuscle myosin II is involved in morphogenesis[74,90,91].

\section{BIOMECHANICS OF HEART LOOPING}

It appears inescapable that interactions involving cytoskeletal components are responsible for biomechanical forces within the heart and dorsal mesocardial folds. These candidate forces include differential growth[29], cardiac jelly swelling[92], active cell shape changes[46], and cytoskeletal contractions $[44,47,93]$. Some of the biomechanical forces and properties of the heart tube during looping have been described and modeled[94-102].

It is suggested that it is not by chance alone that looping occurs concomitantly with onset of rhythmic heart contractions and initiation of blood flow. Heart tube bending occurs in the mouse embryo at the same time as the cardimyocytes begin to contract and maintain some blood circulation on embryonic day (ED) 8.5-9.0. By ED 10.5 two complete extraembryonic circulations, the yolk sac and the placental, have been established, and are feeding increasing volumes of blood into the heart. By day 14 both the definitive pattern of the prenatal circulatory system and the definitive four-chambered shape of the heart are established. Thus, looping occurs simultaneously with increasing blood flow and the associated stresses on the endocardium. Seemingly, these forces are transmitted through the cardiac jelly to the heart wall to affect cardiomyocyte contractility and rate. Understanding the interrelatedness of blood flow and mechanotransduction involving the cytoskeleton during heart looping will be relevant for a mechanistic understanding of this central defining process of cardiogenesis. Results from early 
experiments indicated that normally the cardiac jelly is necessary to augment blood flow by its compressive forces[103]. From our own analyses on hemodynamics of the mouse embryonic heart, the valveless tubular heart has diastolic and systolic blood flow without regurgitation and acts as if valves were present[104]. Early myocardial contractions lead to associated forces of pulsatile blood flow. Over time and during looping these forces increase enabling cardiac function. Shear stress and changes in blood flow are reported to have significant roles in cardiac morphogenesis[105,106].

Creation of abnormal flow patterns, such as by use of a venous clip were reported to cause malformations similar to those seen in knockouts for genes such as endothelin-1 (ET-1)[107,108,109]. Shear stress is defined as the product of the viscosity of blood and the velocity gradient (which is essentially an indicator of the distribution of velocities throughout the cross-section of the vessel). For a simple tube geometry, the shear stress is proportional to flow rate and inversely proportional to $\mathrm{R}^{3}$, where $\mathrm{R}$ is the radius of the vessel. Based on this, one would expect that higher stress would be found in areas of constriction or narrowing, and lower in larger structures such as the developing atria. Based on these assumptions, the pattern of expression of shear stress responsive genes Kruppel-like factor (KLF-2), ET-1 and nitric oxide synthase (NOS-3) have been examined in the developing heart. It was shown that KLF-2 is expressed in areas expected to have higher shear stress, and changes in ET-1 and NOS-3 expression through development appear to be related to changes in shear stress based on the changes in size and shape of the developing structures[110]. We have also detected a high level of flectin expression in a region of high shear stress in association with a narrowing of the cardiac tube within the sinoatrial region (Fig. 4). Shear stress is highly dependent on geometry. For example, there will be an uneven distribution of shear stress along the walls of a curved vessel. For a given geometry, there are also differences in shear stress distributions and cellular responses to shear stresses in pulsatile flow, as compared to steady flow. Thus, both morphometric changes and timing of heart contractions may play a role in determining stress distributions, and thus further morphogenetic changes, due to responses to stress to tightly coordinate heart structure and function[31,56].

It is difficult at best to measure shear stress at any particular location. Thus, precise mapping of shear stress is not feasible. An attempt has been made to determine more precisely flow patterns in Stage 10 and 11 human embryo hearts by converting images to computational fluid dynamic (CFD) models[111]. CFD seeks numerical approximations to equations of motion that represent the physics of blood flow, providing maps of quantities such as velocity and pressure throughout the model. Shear stresses can also be computed from these data. The simulations did indeed predict features of observed blood flow patterns. Digital particle image velocimetry and optical coherence tomography (OCT) are techniques with the potential to provide quantitative information regarding blood flows[112,113], that could be used to ensure validity of the simulations and increase confidence in the calculations of the shear stresses that cannot be measured directly.

The biomechanical properties of the cardiac jelly and myocardium have been explored[96]. The cardiac jelly in HH stage 12 hearts was found to be "softer" than the vitreous body of the eye, and experiences compressive stresses due to pressure exerted within the heart tube and the action of the myocardium. During looping, the inner curvature of the heart tube is stiffer than the outer curvature [114]. In later stages, the myocardium becomes increasingly stiffer with age. This occurs as sarcomeres are formed and the tissue becomes better organized[96], but stiffening also occurs when pressure in the developing heart increases (for example, during chamber septation)[115]. Material properties of the dorsal aorta and systemic arteries also adapt to increased pressure[116]. It is unclear whether changes in material properties are causative or merely consequences of heart looping and development. What is clear is that there are complex interactions between the fluid mechanics and solid mechanics of the developing heart that warrant further study.

Transmission of myocardial contractile forces through the cardiac jelly may involve cell focal adhesions with the ECM molecules of the basal lamina. The generation of forces to accommodate increasing stresses thus can be linked with the myocardial cytoskeleton via cell processes that extend and 

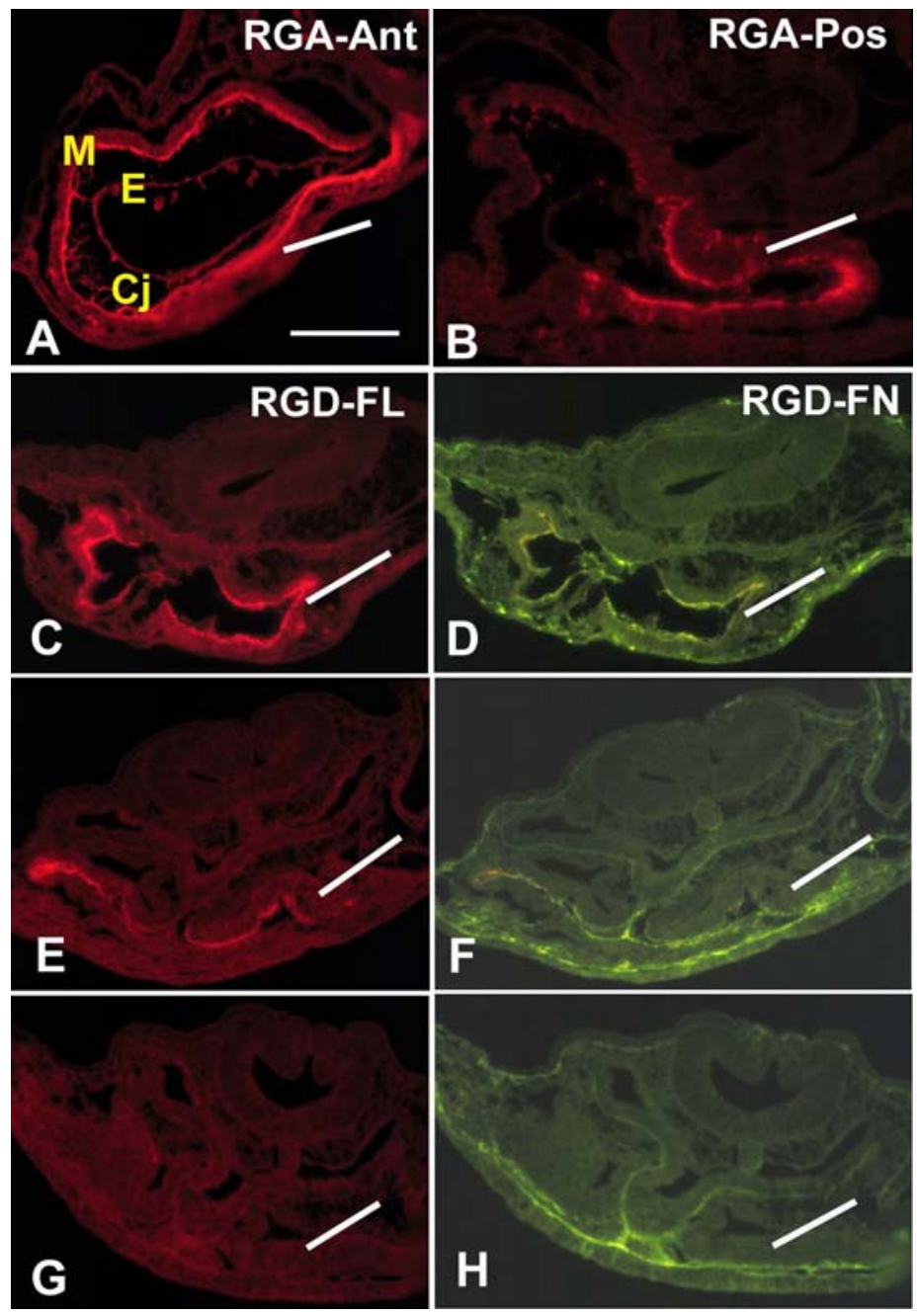

FIGURE 4. Exposure of HH stage 5 chick embryos to RGD peptides results in an inhibition of normal heart looping and a decrease of FL expression, as well as a decrease in the cardiac jelly compartment of the developing heart. Panels A and B show an embryo that was exposed to control RGA-containing peptides. The heart displays normal FL expression in the basal side of the myocardium and in the cardiac jelly as seen in a section through the anterior (Ant) part of the looping heart (A), and in a more posterior (Pos) section through the same heart that continues to show FL expression primarily in the left side of the heart tube (B). Panels $\mathrm{C}-\mathrm{H}$ depict results of embryonic exposure to RGD-containing peptides. Panels $\mathrm{C}, \mathrm{E}$, and $\mathrm{G}$ show an anterior to posterior decrease of FL within the developing heart (white lines point to developing cardiac tissue) on exposure to the RGD peptide in relation to $\mathrm{FN}$ in panels $\mathrm{D}, \mathrm{F}$, and $\mathrm{H}$ that continues to be expressed throughout the heart regions. It is also evident that there is a decrease in ECM production of the cardiac jelly with RGD-peptide inhibition. Magnification bar $=120 \mu \mathrm{m}$.

interact with the ECM components associated with the basal layer of the myocardium. Similarly, monocilia have been shown on embryonic endocardial-endothelial cells that are postulated to function as fluid shear stress sensors[117]. The likelihood that cardiomyocyte cell extensions are integrin mechanosensor related is based on several observations: Already early in development cardiac cells express integrin $\beta 1$ subunit[88]. Myocardial cells are associated with FN in the basement membrane (Fig. 5), and the myocardial cell processes do not express acetylated tubulin (Fig. 6), that is detected in true 
microcilia. Therefore we suggest that basal myocardiocyte cell processes may act as mechanosensors to mediate the exchange of inside-out and outside-in information through transmembrane integrin receptormediated interactions with extracellular matrix molecules within the myocardial basal lamina. This appears also to be the case in the zebrafish heart where an integrin-linked kinase was shown to be a component of the cardiac mechanical stretch sensor to control contractility in the zebrafish heart[118].

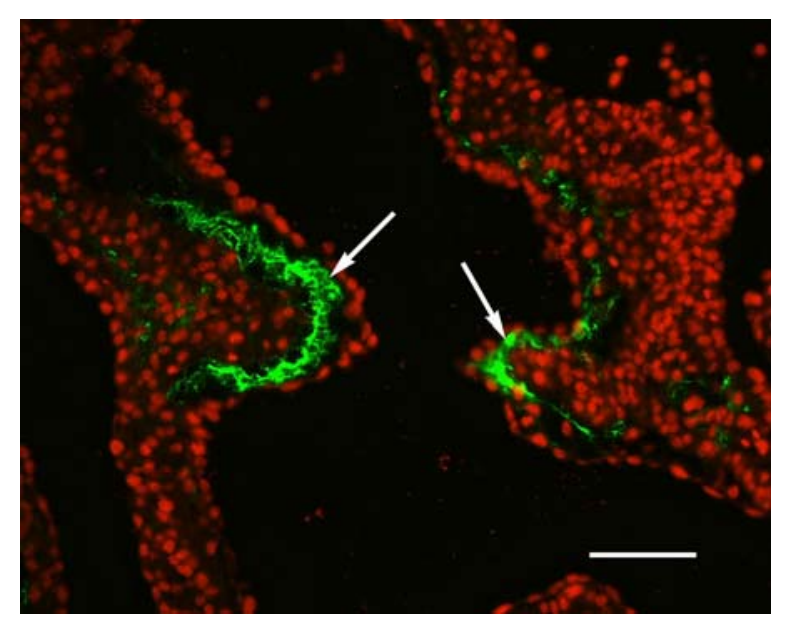

FIGURE 5. Flectin (green fluorescence; see arrows) is evident in the ECM at $\mathrm{HH}$ stage 17 in the sinus venosus region of the chick heart where a narrowing of the heart tube is observed. This is a region where a high shear stress of blood flow would be expected. Magnification bar $=50 \mathrm{um}$.

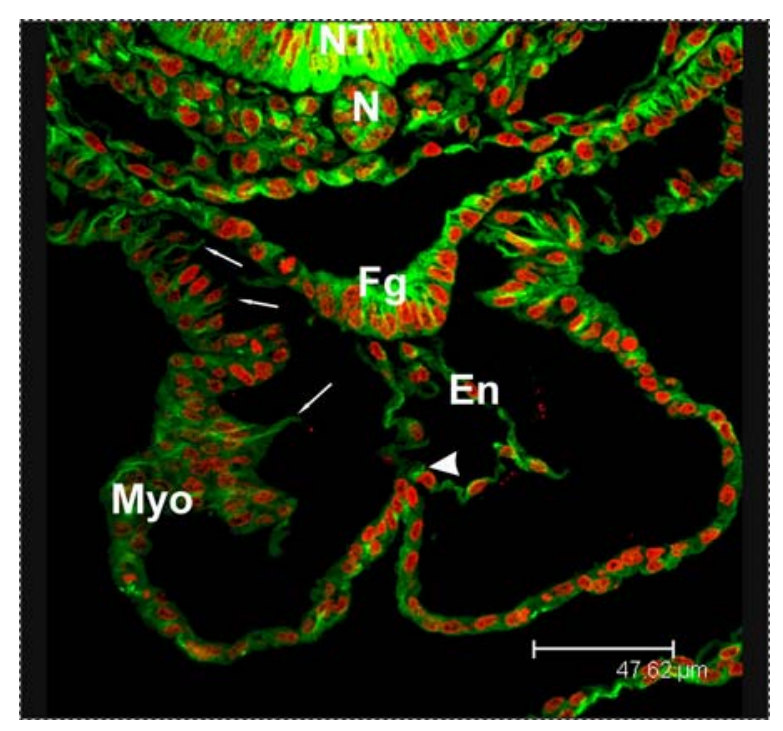

FIGURE 6. HH stage 11 chick heart immunostained for acetylated tubulin. Myocardial cell processes extending into the cardiac jelly (see arrows) do not express acetylated tubulin that is observed usually in microcilia (arrowhead) and that are associated with endocardial-endothelial cells. This lack of tubulin expression in cardiomyocyte cell extensions into the ECM of the basal lamina and the RGD experiments suggest that myocardial mechanosensing of forces associated with blood flow would most likely be through integrin-mediated signaling. NT, neural tube; N, notochord; Fg, foregut; Myo, myocardium; En, endocardium. Magnification bar $=47.62 \mu \mathrm{m}$. 
The presence of mechanoreceptors would allow signal transduction and feedback from the myocardial wall and endocardium to accommodate blood flow increases, as well as possibly to regulate completion of looping. It appears logical to deduce that evolution has enabled the organization of the cytoskeleton for both generation of force and the ability to undergo deformation while adapting to force.

\section{ACKNOWLEDGMENTS}

The research in relation to looping, FL, and NMHC-II studies was generously supported by grants from American Heart Association Established Investigator Grant and from the Suncoast Cardiovascular Research and Education Foundation founded by Helen Harper Brown (to KKL). The following collaborations are greatly appreciated: Dr. Isao Shiraishi at the Kyoto Prefectural University of Medicine in Japan for generation of Fig. 3; Dr. Guoying Huang of Shanghai Medical University for generation of the RGD data shown in Fig. 4 during his postdoctoral training in my lab (KKL); and Dr. Beerend Hierck and his student Kim Van der Heiden at the Leiden University Medical Center in the Netherlands for preparation of Figs. 5 and 6.

\section{REFERENCES}

1. Levin, M., Johnson, R.L., Stern, C.D., Kuehn, M., and Tabin, C. (1995) A molecular pathway determining left-right asymmetry in chick embryogenesis. Cell 82, 803-814.

2. Isaac, A., Sargent, M.G., and Cooke, J. (1997) Control of vertebrate left-right asymmetry by a snail-related zinc finger gene. Science 275, 1301-1304.

3. Pagan-Westphal, S.M. and Tabin, C.J. (1998) The transfer of left-right positional information during chick embryogenesis. Cell 93, 25-35.

4. Piedra, M.E., Icardo, J.M., Albajar, M., Rodriguez-Rey, J.C., and Ros, M.A. (1998) Pitx2 participates in the late phase of the pathway controlling left-right asymmetry. Cell 94, 319-324.

5. Franco, D. and Campione, M. (2003) The role of Pitx2 during cardiac development. Linking left-right signaling and congenital heart diseases. Trends Cardiovasc. Med. 13, 157-163.

6. Bamforth, S.D., Branganca, J., Farthing, C.R., Schneider, J.E., Broadbent, C., Michell, A.C., Clarke, K., Neubauer, S., Norris, D.P., Brown, N.A., Anderson, R.H., and Bhattacharya, S. (2004) Cited2 controls left-right patterning and heart development through a Noda-Pitx2c pathway. Nat. Genet. 36, 1189-1196.

7. Bisgrove, B.W., Morellli, S.H., and Yost, H.J. (2003) Genetics of human laterality disorders: insights from vertebrate model systems. Annu. Rev. Genomics Hum. Genet. 4, 1-32.

8. McGrath, J., Somlo, S., Makova, S., Tian, X., and Brueckner, M. (2003) Two populations of node monocilia initiate left-right asymmetry in the mouse. Cell 114, 61-73.

9. $\quad$ Essner, J.J., Vogan, K.J., Wagner, M.K., Tabin, C.J., Yost, H.J., and Brueckner, M. (2002) Conserved function for embryonic nodal cilia. Nature 418, 37-38.

10. Supp, D.M., Brueckner, M., Kuehn, M.R., Witte, D.P., Lowe, L.A., McGrath, J., Corrales, J., and Potter, S.S. (1999) Targeted deletion of the ATP binding domain of left-right dynein confirms its role in specifying development of leftright asymmetries. Development 126, 5495-5504.

11. Nonaka, S., Tanaka, Y., Okada, Y., Takeda, S., Harada, A., Kanai, Y., Kido, M., and Hirokawa, N. (1998) Randomization of left-right asymmetry due to loss of nodal cilia generating leftward flow of extraembryonic fluid in mice lacking KIF3B motor protein. Cell 95, 829-837.

12. Tanaka, Y., Okada, Y., and Hirokawa, N. (2005) FGF-induced vesicular release of Sonic hedgehog and retinoic acid in leftward nodal flow is criticql for left-right determination. Nature 435, 172-177.

13. Huangfu, D. and Anderson, K.V. (2005) Cilia and Hedgehog responsiveness in the mouse. Proc. Natl. Acad. Sci. U. S. A. 102, 11325-11330.

14. Hirokawa, N., Tanaka, Y., Okada, Y., and Takeda, S. (2006) Nodal flow and the generation of left-right asymmetry. Cell 125, 33-45.

15. Linask, K.K., Han, M.D., Artman, M., and Ludwig, C.A. (2001) Sodium-calcium exchanger (NCX-1) and calcium modulation. NCX protein expression patterns and regulation of early heart development. Dev. Dyn. 221, $249-264$.

16. Levin, M. and Mercola, M. (1999) Gap junction-mediated transfer of left-right patterning signals in the early chick blastoderm is upstream of Shh asymmetry in the node. Development 126, 4703-4714.

17. Levin, M. (2006) Is the early left-right axis like a plant, a kidney, or a neuron? The integration of physiological signals in embryonic asymmetry. Birth Defects Res. C Embryo Today 78, 191-223. 
18. Nakamura, T., Mine, N., Nakaguchi, E., Mochizuki, A., Yamamoto, M., Yashiro, K., Meno, C., and Hamada, H. (2006) Generation of robust left-right asymmetry in the mouse embryo requires a self-enhancement and lateralinhibition system. Dev. Cell 11, 495-504.

19. Lowe, L.A., Supp, D.M., Sampath, K., Yokoyama, T., Wright, C.V.E., Potter, S.S., Overbeek, P., and Kuehn, M.R. (1996) Conserved left-right asymmetry of nodal expression and alterations in murine situs inversus. Nature 381, 158161.

20. Lohr, J.L., Danos, M.C., and Yost, H.J. (1997) Left-right asymmetry of a nodal-related gene is regulated by dorsoanterior midline structures during Xenopus development. Development 124, 1465-1472.

21. Kitamura, K., Miura, H., Miyagawa-Tomita, S., Yanazawa, M., Katoh-Fukui, Y., Suzuki, R., Ohuchi, H., Suehiro, A., Motegi, Y., Nakahara, Y., Kondo, S., and Yokoyama, M. (1999) Mouse Pitx2 deficiency leads to anomalies of the ventral body wall, heart, extra- and periocular mesoderm and right pulmonary isomerism. Development 126, 57495758.

22. Liu, C., Liu, W., Lu, M.F., Brown, N.A., and Martin, J.F. (2001) Regulation of left-right asymmetry by thresholds of Pitx2c activity. Development 128, 2039-2048.

23. Kioussi, C., Briata, P., Baek, S., Rose, D., Hamblet, N., Herman, T., Ohgi, K., et al. (2002) Identification of a Wnt/Dvl/B-Catenin - Pitx2 pathway mediating cell-type-specific proliferation during development. Cell 111, $673-685$.

24. Linask, K., Han, M., Linask, K., Schlange, T., and Brand, T. (2003) Effects of antisense misexpression of CFC on downstream flectin protein expression during heart looping. Dev. Dyn. 228, 217-230.

25. Linask, K.K., Yu, X., Chen, Y.P., and Han, M.D. (2002) Directionality of heart looping: effects of Pitx2c misexpression on flectin asymmetry and midline structures. Dev. Biol. 246, 407-417.

26. Tsuda, T., Majumder, K., and Linask, K.K. (1998) Differential expression of flectin in the extracellular matrix and left-right asymmetry in mouse embryonic heart during looping stages. Dev. Genet. 23, 203-214.

27. Tsuda, T., Philp, N., Zile, M.H., and Linask, K.K. (1996) Left-right asymmetric localization of flectin in the extracellular matrix during heart looping. Dev. Biol. 173, 39-50.

28. Kelly, R.G. (2005) Molecular inroads into the anterior heart field. Trends Cardiovasc. Med. 15, 51-56.

29. Linask, K.K., Han, M., Cai, D.H., Brauer, P.R., and Manisastry, S.M. (2005) Cardiac morphogenesis: matrix metalloproteinase coordination of cellular mechanisms underlying heart tube formation and directionality of heart looping. Dev. Dyn. 233, 739-753.

30. Linask, K.K. and Lash, J.W. (1998) Morphoregulatory mechanisms underlying early heart development: precardiac stages to the looping, tubular heart. In Living Morphogenesis of the Heart. Cruz, M.D.I. and Markwald, R., Eds. Birkhauser, Boston, MA.

31. Linask, K. (2003) Regulation of heart morphology: current molecular and cellular perspectives on the coordinated emergence of cardiac form and function. Birth Defects Res. C Embryo Today 69, 14-24.

32. DeHaan, R.L. (1964) Cell interactions and oriented movements during development. J. Exp. Zool. 157, $127-138$.

33. Rosenquist, G.C. and DeHaan, R.L. (1966) Migration of precardiac cells in the chick embryo: a radioautographic study. Carnegie Inst. Wash. Contrib. Embryol. 38, 111-121.

34. Linask, K.K. and Lash, J.W. (1988) A role for fibronectin in the migration of avian precardiac cells. I. Dose dependent effects of fibronectin antibody. Dev. Biol. 129, 315-323.

35. Linask, K.K. and Lash, J.W. (1988) A role for fibronectin in the migration of avian precardiac cells. II. Rotation of the heart-forming region during different stages and its effects. Dev. Biol. 129, 324-329.

36. Linask, K.K. and Lash, J.W. (1986) Precardiac cell migration: fibronectin localization at mesoderm-endoderm interface during directional movement. Dev. Biol. 114, 87-101.

37. Trinh, L.A. and Stainier, D.Y. (2003) Epithelial organization and migration of the myocardial precursors require cellsubstratum interaction in zebrafish. Mol. Biol. Cell 14, 140a.

38. Trinh, L.A. and Stainier, D.Y.R. (2004) Fibronectin regulates epithelial organization during myocardial migration in zebrafish. Dev. Cell 6, 371-382.

39. Linask, K.K. (1992) N-cadherin localization in early heart development and polar expression of Na, K-ATPase, and integrin during pericardial coelom formation and epithelialization of the differentiating myocardium. Dev. Biol. 151, $213-224$.

40. Linask, K.K., Knudsen, K.A., and Gui, Y.H. (1997) N-cadherin-catenin interaction: necessary component of cardiac cell compartmentalization during early vertebrate heart development. Dev. Biol. 185, 148-164.

41. Kupperman, E., An, S., Osborne, N., Waldron, S., and Stainier, D.Y.R. (2000) A spingosine-1-phosphate receptor regulates cell migration during vertebrate heart development. Nature 406, 192-195.

42. Speder, P., Adam, G., and Noselli, S. (2006) Type ID unconventional myosin controls left-right asymmetry in Drosophila. Nature 440, 803-807.

43. Pollard, T.D. (2003) The cytoskeleton, cellular motility, and the reductionist agenda. Nature 422, 741-745.

44. Itasaki, N., Nakamura, H., Sumida, H., and Yasuda, M. (1991) Actin bundles on the right side in the caudal part of the heart tube play a role in dextro-looping in the embryonic chick heart. Anat. Embryol. 183, 29-39.

45. Manasek, F.J. (1976) Heart development: interactions involved in cardiac morphogenesis. In The Cell Surface in Animal Embryogenesis and Development. Poste, G. and Nicolson, G.L., Eds. Elsevier, Amsterdam. pp. 545-598.

46. Manasek, F.J., Burnside, M.B., and Waterman, R.E. (1972) Myocardial cell shape change as a mechanism of embryonic looping. Dev. Biol. 29, 349-371. 
47. Latacha, K.S., Remond, M.C., Ramasubramanian, A., Chen, A.Y., Elson, E.L., and Taber, L.A. (2005) Role of actin polymerization in bending of the early heart tube. Dev. Dyn. 233, 1272-1286.

48. Shiraishi, I., Takamatsu, T., Minamikawa, T., and Fujita, S. (1992) 3-D observation of actin filaments during cardiac myofibrillogenesis in chick embryo using a confocal laser scanning microscope. Anat. Embryol. 185, 401-408.

49. Price, R.L., Chintanowonges, C., Shiraishi, I., Borg, T.K., and Terracio, L. (1996) Local and regional variations in myofibrillar patterns in looping rat hearts. Anat. Rec. 245, 83-93.

50. Shiraishi, I., Takamatsu, T., and Fujita, S. (1995) Three-dimensional observation with a confocl scanning laser microscope of fibronectin immunolabeling during cardiac looping in the chick embryo. Anat. Embryol. 191, 183-189.

51. Linask, K.K. (1992) Regulatory role of cell adhesion molecules in early heart development. In Formation and Differentiation of Early Embryonic Mesoderm. Bellairs, R., Sanders, E.J., and Lash, J.W., Eds. Plenum, New York. pp. 301-313.

52. Kostetskii, I., Li, J., Xiong, Y., Zhou, R., Ferrari, V.A., Patel, V.V., Molkentin, J.D., and Radice, G.L. (2005) Induced deletion of the N-cadherin gene in the heart leads to dissolution of the intercalated disc structure. Circ. Res. 96, 346-354.

53. Shiraishi, I., Takamatsu, T., and Fujita, S. (1993) 3-D observation of N-cadherin expression during cardiac myofibrillogenesis of the chick embryo using a confocal laser scanning microscope. Anat. Embryol. (Berl.) 187, 115120.

54. Li, J., Patel, V.V., Kostetskii, I., Xiong, Y., Chu, A.F., Jacobson, J.T., Yu, C., Morley, G.E., Molkentin, J.D., and Radice, G.L. (2005) Cardiac-specific loss of N-cadherin leads to alteration in connexins with conduction slowing and arrhythmogenesis. Circ. Res. 97, 474-481.

55. Matsuda, T., Takahashi, K., Nariai, T., Ito, T., Takatani, T., Fujio, Y., and Azuma, J. (2005) N-cadherin-mediated cell adhesion determines the plasticity for cell alignment in response to mechanical stretch in cultured cardiomyocytes. Biochem. Biophys. Res. Commun. 326, 228-232.

56. Linask, K.K., Manisastry, S.M., and Han, M. (2005) Cross talk between cell-cell and cell-matrix adhesion signaling pathways during heart organogenesis: implication for cardiac birth defects. Microsc. Microanal. 11, 200-208.

57. Lash, J.W., Rhee, D., Zibrida, J.T., and Philp, N. (1992) A monoclonal antibody that reacts with the ventro-caudal quadrant of newly formed somites. In: Formation and Differentiation of early embryonic mesoderm. Bellairs, R., Sanders, E.J., and Lash, J.W. eds. New York: Plenum Press, pp. 169-180.

58. Mieziewska, K., Szel, A., Van Veen, T., Aguirre, G.D., and Philp, N. (1994) Redistribution of insoluble interphotoreceptor matrix components during photoreceptor differentiation in the mouse retina. J. Comp. Neurol. 345, 115-124.

59. Mieziewska, K.E., Devenny, J., van Veen, T., Aguirre, G.D., and Philp, N. (1994) Characterization of a developmentally regulated component of ocular extracellular matrix that is evolutionarily conserved. Invest. Ophthalmol. Vis. Sci. 35, 1608.

60. Mieziewska, K. (1996) The interphotoreceptor matrix, a space in sight. Microsc. Res. Tech. 35, 463-471.

61. Lu, W., Seeholzer, S.H., Han, M., Chen, J., Philp, N.J., Farthing, C.R., Bhattacharya, S., Shiraishi, I., Steele, A., Arnold, A.S., and Linask, K.K. (2007) Cellular nonmuscle myosins NMHC-IIA and NMHC-IIB expression and modulation during vertebrate heart looping: Identification of flectin., Submitted.

62. Du, A., Sanger, J.M., Linask, K.K., and Sanger, J.W. (2003) Myofibrillogenesis in the first cardiomyocytes formed from isolated quail precardiac mesoderm. Dev. Biol. 257, 382-394.

63. Linz-McGillem, L.A., and Alliegro, M.C. (2003) Myosin II in retinal pigmented epithelial cells: evidence for an association with membranous vesicles. Exp. Eye Res. 76, 543-552.

64. Marigo, V., Nigro, A., Pecci, A., Montanaro, D., Di Stazio, M., Balduini, C.L., and Savoia, A. (2004) Correlation between the clinical phenotype of MYH9-related disease and tissue distribution of class II nonmuscle myosin heavy chains. Genomics 83, 1125-1133.

65. Mhatre, A.N., Kim, Y., Brodie, H.A., and Lalwani, A.K. (2003) Macrothrombocytopenia and progressive deafness is due to a mutation in MYH9. Otol. Neurotol. 24, 205-209.

66. Mhatre, A.N., Li, J., Kim, Y., Coling, D.E., and Lalwani, A.K. (2004) Cloning and developmental expression of nonmuscle myosin IIA (Myh9) in the mammalian inner ear. J. Neurosci. Res. 76, 296-305.

67. Shiraishi, M., Wang, X., Walsh, M.P., Kargacin, G., Loutzenhiser, K., and Loutzenhiser, R. (2003) Myosin heavy chain expression in renal afferent and efferent arterioles: relationship to contractile kinetics and function. FASEB J. 17, 2284-2286.

68. Linask, K.K., Han, M.D., Linask, K.L., Schlange, T., and Brand, T. (2003) Effects of antisense misexpression of CFC on downstream flectin protein expression during heart looping. Dev. Dyn. 228, 217-230.

69. Baldwin, H.S. and Solursh, M. (1989) Degradation of hyaluronic acid does not prevent looping of the mammalian heart in situ. Dev. Biol. 136, 555-559.

70. Butler, J.K. (1952) An Experimental Analysis of Cardiac Loop Formation in the Chick [M.A. Thesis]. The University of Texas, Austin.

71. Remond, M.C., Fee, J.A., Elson, E.L., and Taber, L.A. (2006) Myosin-based contraction is not necessary for cardiac c-looping in the chick embryo. Anat. Embryol. (Berl.) 211, 443-454.

72. Conti, M.A., Even-Ram, S., Liu, C., Yamada, K.M., and Adelstein, R.S. (2004) Defects in cell adhesion and the visceral endoderm following ablation of nonmuscle myosin heavy chain II-A in mice. J. Biol. Chem. 279, 4126341266. 
73. Tullio, A.N., Accili, D., Ferrans, V.J., Yu, Z.X., Takeda, K., Grinberg, A., Westphal, H., Preston, Y.A., and Adelstein, R.S. (1997) Nonmuscle myosin II-B is required for normal development of the mouse heart. Proc. Natl. Acad. Sci. U. S. A. 94, 12407-12412.

74.. Huang, H., Paliouras, M., Rambaldi, I., Lasko, P., and Featherstone, M. (2003) Nonmuscle myosin promotes cytoplasmic localization of PBX. Mol. Cell. Biol. 23, 3636-3645.

75. Bishop, A.L. and Hall, A. (2000) Rho GTPases and their effector proteins. Biochem. J. 348(Pt 2), $241-255$.

76. Matsui, T., Amano, M., Yamamoto, T., Chihara, K., Nakafuku, M., Ito, M., Nakano, T., Okawa, K., Iwamatsu, A., and Kaibuchi, K. (1996) Rho-associated kinase, a novel serine/threonine kinase, as a putative target for small GTP binding protein Rho. EMBO J. 15, 2208-2216.

77. Amano, M., Ito, M., Kimura, K., Fukata, Y., Chihara, K., Nakano, T., Matsuura, Y., and Kaibuchi, K. (1996) Phosphorylation and activation of myosin by Rho-associated kinase (Rho-kinase). J. Biol. Chem. 271, 20246-20249.

78. Wei, L., Roberts, W., Wang, L., Yamada, M., Zhang, S., Zhao, Z., Rivkees, S.A., Schwartz, R.J., and ImanakaYoshida, K. (2001) Rho kinases play an obligatory role in vertebrate embryonic organogenesis. Development 128, 2953-2962.

79. Uehata, M., Toshimasa, I., Satoh, H., Ono, T., Kawahara, T., Morishita, T., Tamakawa, H., Yamagami, K., Inui, J., Maekawa, M., and Narumiya, S. (1997) Calcium sensitization of smooth muscle mediated by a Rho-associated protein kinase in hypertension. Nature 389, 990-994.

80. Wei, L., Imanaka-Yoshida, K., Wang, L., Zhan, S., Schneider, M.D., DeMayo, F.J., and Schwartz, R.J. (2002) Inhibition of Rho family GTPases by Rho GDP dissociation inhibitor disrupts cardiac morphogenesis and inhibits cardiomyocyte proliferation. Development 129, 1705-1714.

81. Kawabata, S., Usukura, J., Morone, N., Ito, M., Iwamatsu, A., Kaibuchi, K., and Amano, M. (2004) Interaction of Rho-kinase with myosin II at stress fibres. Genes Cells 9, 653-660.

82. Turner, N.A., O'Regan, D.J., Ball, S.G., and Porter, K.E. (2005) Simvastatin inhibits MMP-9 secretion from human saphenous vein smooth muscle cells by inhibiting the RhoA/ROCK pathway and reducing MMP-9 mRNA levels. FASEB J. 19, 804-806.

83. Nelson, C.M., Pirone, D.M., Tan, J.L., and Chen, C.S. (2004) Vascular endothelial-cadherin regulates cytoskeletal tension, cell spreading, and focal adhesions by stimulating RhoA. Mol. Biol. Cell 15, 2943-2953.

84. Torsoni, A.S., Marin, T.M., Velloso, L.A., and Franchini, K.G. (2005) RhoA/ROCK signaling is critical to FAK activation by cyclic stretch in cardiac myocytes. Am. J. Physiol. Heart Circ. Physiol. 289(4), H1488-1496.

85. Wei, Q. and Adelstein, R.S. (2002) Pitx2a expression alters actin-myosin cytoskeleton and migration of HeLa cells through Rho GTPase signaling. Mol. Biol. Cell 13, 683-697.

86. Verdier, V., Chen, G.C., and Settleman, J. (2006) Rho-kinase regulates tissue morphogenesis via non-muscle myosin and LIM-kinase during Drosophila development. BMC Dev. Biol. 6, 38-48.

87. Lash, J.W., Linask, K.K., and Yamada, K.M. (1987) Synthetic peptides that mimic the adhesive recognition signal of fibronectin: differential effects on cell-cell and cell-substratum adhesion in embryonic chick cells. Dev. Biol. 123, 411-420.

88. Linask, K.K. and Lash, J.W. (1990) Fibronectin and integrin distribution on migrating precardiac mesoderm cells. Ann. N.Y. Acad. Sci. 588, 417-420.

89. Yost, H.J. (1992) Regulation of vertebrate left-right asymmetries by extracellular matrix. Nature 357, $158-161$.

90. Blake, K.J., Myette, G., and Jack, J. (1998) The products of ribbon and raw are necessary for proper cell shape and cellular localization of nonmuscle myosin in Drosophila. Dev. Biol. 203, 177-188.

91. Blake, K.J., Myette, G., and Jack, J. (1999) ribbon, raw, and zipper have distinct functions in reshaping the Drosophila cytoskeleton. Dev. Genes Evol. 209, 555-559.

92. Manasek, F., Kulikowski, R., Nakamura, Q., Nguyehphuc, Q., and Lacktis, J. (1984) Early heart development: a new model of cardiac morphogenesis. In Growth of the Heart in Health and Disease. Radovan, Z., Ed. Raven, New York. pp. 105-130.

93. Taber, L.A., Lin, I.E., and Clark, E. (1995) Mechanics of cardiac looping. Dev. Dyn. 203, 42-50.

94. Zamir, E.A. and Taber, L.A. (2004) On the effects of residual stress in microindentation tests of soft tissue structures. J. Biomech. Eng. 126, 276-283.

95. Voronov, D.A., Alford, P.W., Xu, G., and Taber, L.A. (2004) The role of mechanical forces in dextral rotation during cardiac looping in the chick embryo. Dev. Biol. 272, 339-350.

96. Zamir, E.A. and Taber, L.A. (2004) Material properties and residual stress in the stage 12 chick heart during cardiac looping. J. Biomech. Eng. 126, 823-830.

97. Lucitti, J.L., Tobita, K., and Keller, B.B. (2005) Arterial hemodynamics and mechanical properties after circulatory intervention in the chick embryo. J. Exp. Biol. 208, 1877-1885.

98. Tobita, K., Garrison, J.B., Liu, L.J., Tinney, J.P., and Keller, B.B. (2005) Three-dimensional myofiber architecture of the embryonic left ventricle during normal development and altered mechanical loads. Anat. Rec. A Discov. Mol. Cell. Evol. Biol. 283, 193-201.

99. Schroder, E.A., Tobita, K., Tinney, J.P., Foldes, J.K., and Keller, B.B. (2002) Microtubule involvement in the adaptation to altered mechanical load in developing chick myocardium. Circ. Res. 91, 353-359.

100. Tobita, K. and Keller, B.B. (2000) Maturation of end-systolic stress-strain relations in chick embryonic myocardium. Am. J. Physiol. Heart Circ. Physiol. 279, H216-224. 
101. Manner, J. (2004) On rotation, torsion, lateralization, and handedness of the embryonic heart loop: new insights from a simulation model for the heart loop of chick embryos. Anat. Rec. A Discov. Mol. Cell. Evol. Biol. 278, 481-492.

102. Männer, J. (2000) Cardiac looping in the chick embryo: a morphological review with special reference to terminological and biomechanical aspects of the looping process. Anat. Rec. 259, 248-262.

103. Davis, C.L. (1924) The cardiac jelly of the chick embryo. Anat. Rec. 27, 201-202 (Abstr).

104. Gui, Y.H., Linask, K.K., Khowsathit, P., and Huhta, J.C. (1996) Doppler echocardiography of normal and abnormal embryonic mouse heart. Pediatr. Res. 40, 633-642.

105. Hove, J.R., Koster, R.W., Forouhar, A.S., Acevedo-Bolton, G., Fraser, S.E., and Gharib, M. (2003) Intracardiac fluid forces are an essential epigenetic factor for embryonic cardiogenesis. Nature 142, 172-177.

106. Hove, J.R. (2006) Quantifying cardiovascular flow dynamics during early development. Pediatr. Res. 60, 6-13.

107. Hogers, B., DeRuiter, M.C., Gittenberger-de Groot, A.C., and Poelmann, R.E. (1997) Unilateral vitelline vein ligation alters intracardiac blood flow patterns and morphogenesis in the chick embryo. Circ. Res. 80, 473-481.

108. Hogers, B., DeRuiter, M.C., Gittenberger-de Groot, A.C., and Poelmann, R.E. (1999) Extraembryonic venous obstructions lead to cardiovascular malformations and can be embryolethal. Cardiovasc. Res. 41, 87-99.

109. Kurihara, Y., Kurihara, H., Oda, H., Maemura, K., Nagai, R., Ishikawa, T., and Yazaki, Y. (1995) Aortic arch malformations and ventricular septal defect in mice deficient in endothelin-1. J. Clin. Invest. 96, 293-300.

110. Groenendijk, B.C., Hierck, B.P., Gittenberger-De Groot, A.C., and Poelmann, R.E. (2004) Development-related changes in the expression of shear stress responsive genes KLF-2, ET-1, and NOS-3 in the developing cardiovascular system of chicken embryos. Dev. Dyn. 230, 57-68.

111. DeGroff, C.G., Thornburg, B.L., Pentecost, J.O., Thornburg, K.L., Gharib, M., Sahn, D.J., and Baptista, A. (2003) Flow in the early embryonic human heart: a numerical study. Pediatr. Cardiol. 24, 375-380.

112. Jenkins, M.W., Rothenberg, F., Roy, D., Nikolski, V.P., Hu, Z., Watanabe, M., Wilson, D.L., Efimov, I.R., and Rollins, A.M. (2006) 4D embryonic cardiography using gated optical coherence tomography. Optics Expr. 14, 736-748.

113. Vennemann, P., Kiger, K.T., Lindken, R., Groenendijk, B.C., Stekelenburg-de Vos, S., ten Hagen, T.L., Ursem, N.T., Poelmann, R.E., Westerweel, J., and Hierck, B.P. (2006) In vivo micro particle image velocimetry measurements of blood-plasma in the embryonic avian heart. J. Biomech. 39, 1191-1200.

114. Zamir, E.A., Srinivasan, V., Perucchio, R., and Taber, L.A. (2003) Mechanical asymmetry in the embryonic chick heart during looping. Ann. Biomed. Eng. 31, 1327-1336.

115. Miller, C.E., Wong, C.L., and Sedmera, D. (2003) Pressure overload alters stress-strain properties of the developing chick heart. Am. J. Physiol. Heart Circ. Physiol. 285, H1849-1856.

116. Lucitti, J.L., Visconti, R., Novak, J., and Keller, B.B. (2006) Increased arterial load alters aortic structural and functional properties during embryogenesis. Am. J. Physiol. Heart Circ. Physiol. 291, H1919-1926.

117. Van der Heiden, K., Groenendijk, B.C., Hierck, B.P., Hogers, B., Koerten, H.K., Mommaas, A.M., Gittenberger-de Groot, A.C., and Poelmann, R.E. (2006) Monocilia on chicken embryonic endocardium in low shear stress areas. Dev. Dyn. 235, 19-28.

118. Bendig, G., Grimmler, M., Huttner, I.G., Wessels, G., Dahme, T., Just, S., Trano, N., Katus, H.A., Fishman, M.C., and Rottbauer, W. (2006) Integrin-linked kinase, a novel component of the cardiac mechanical stretch sensor, controls contractility in the zebrafish heart. Genes Dev. 20(17), 2361-2372.

119. Hu, H. and Sachs, F. (1997) Stretch-activated ion channels in the heart. J. Mol. Cell Cardiol. 29, 1511-1523.

120. Liu, J., Shrank, B., and Waterston, R.H. (1996) Interaction between a putative mechanosensitive membrane channel and a colagen. Science $273,361-364$.

This article should be cited as follows:

Linask, K.K. and VanAuker, M. (2007) A role for the cytoskeleton in heart looping. TSW Development \& Embryology 2, $29-46$. DOI 10.1100/tswde.2007.61. 

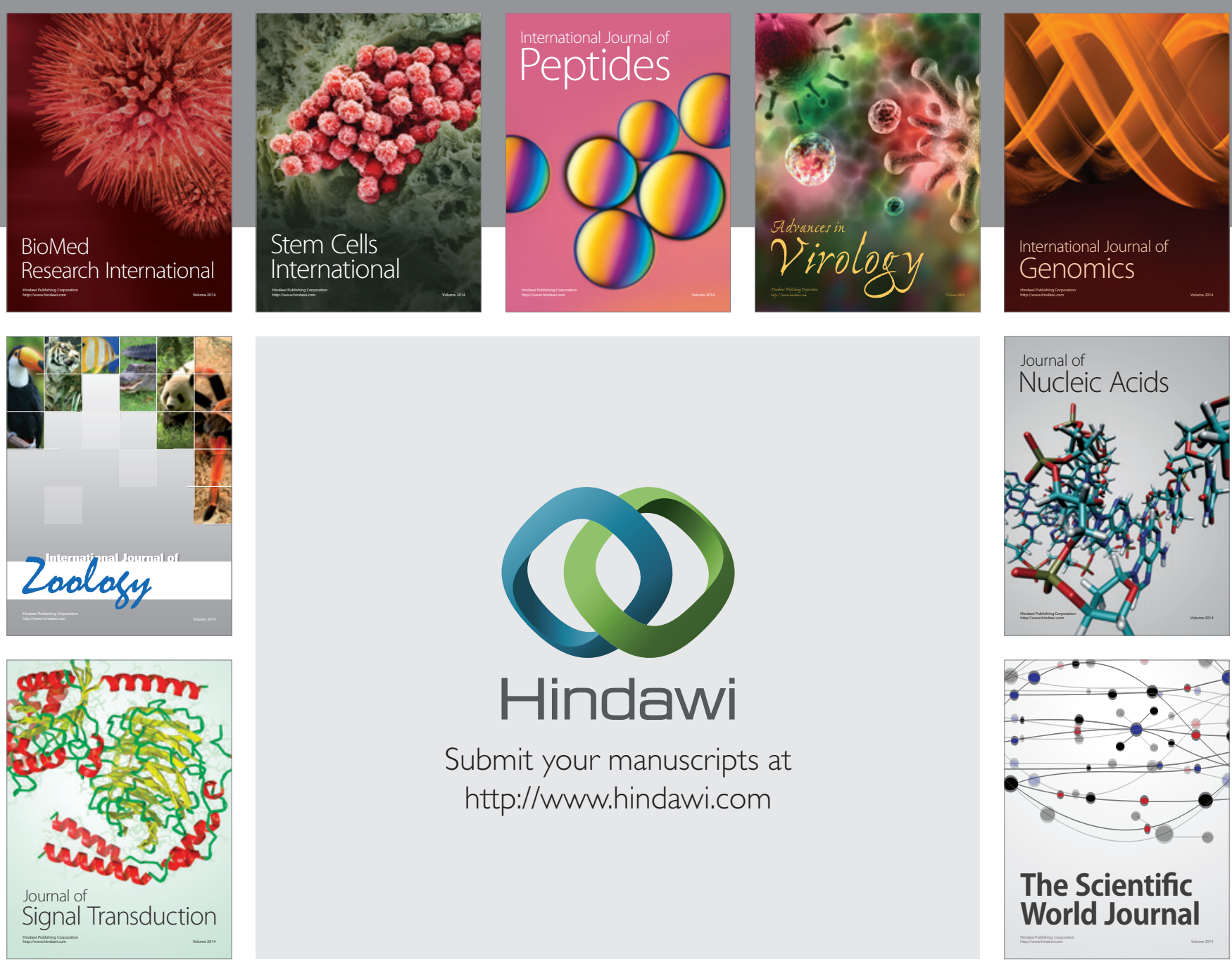

Submit your manuscripts at

http://www.hindawi.com
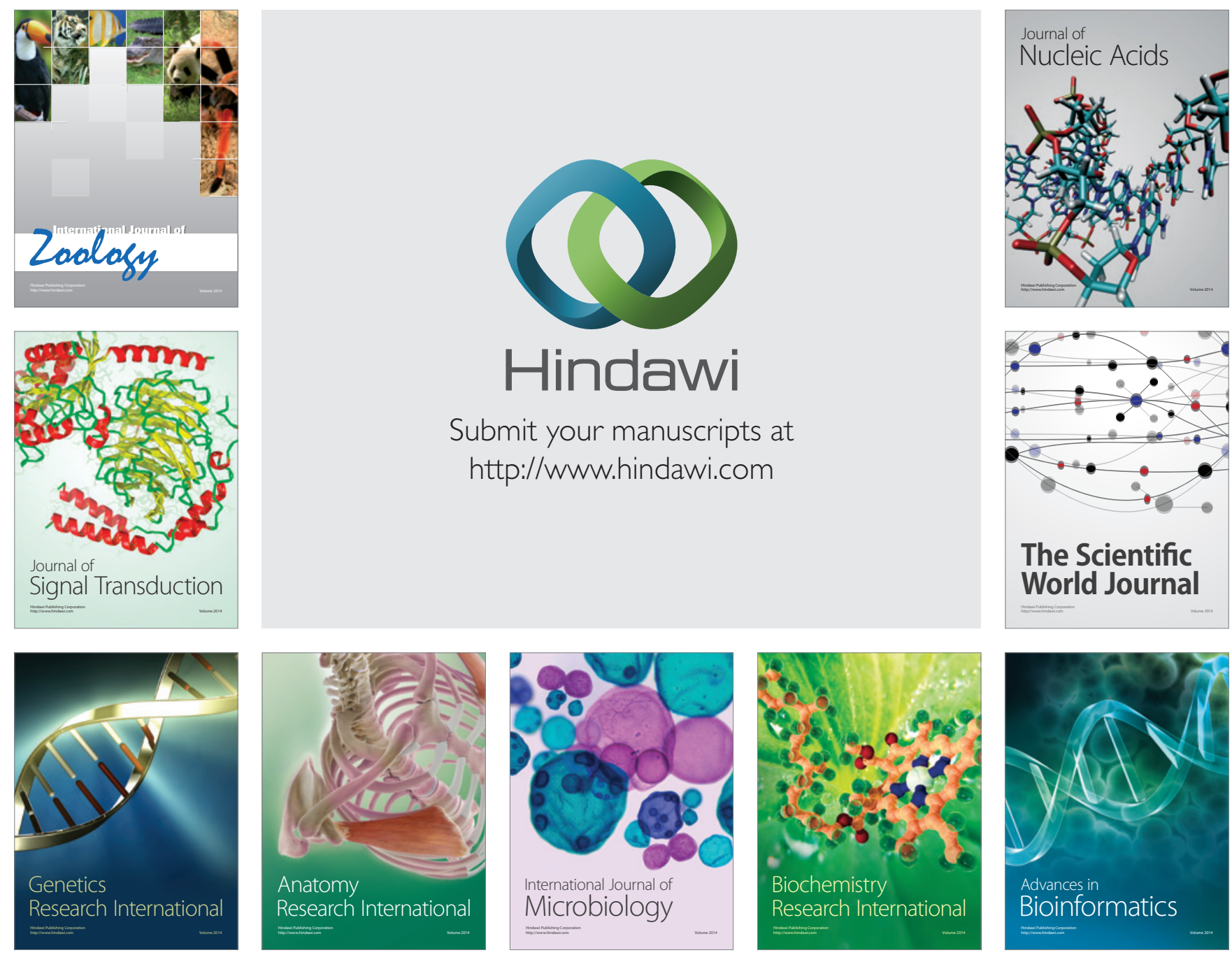

The Scientific World Journal
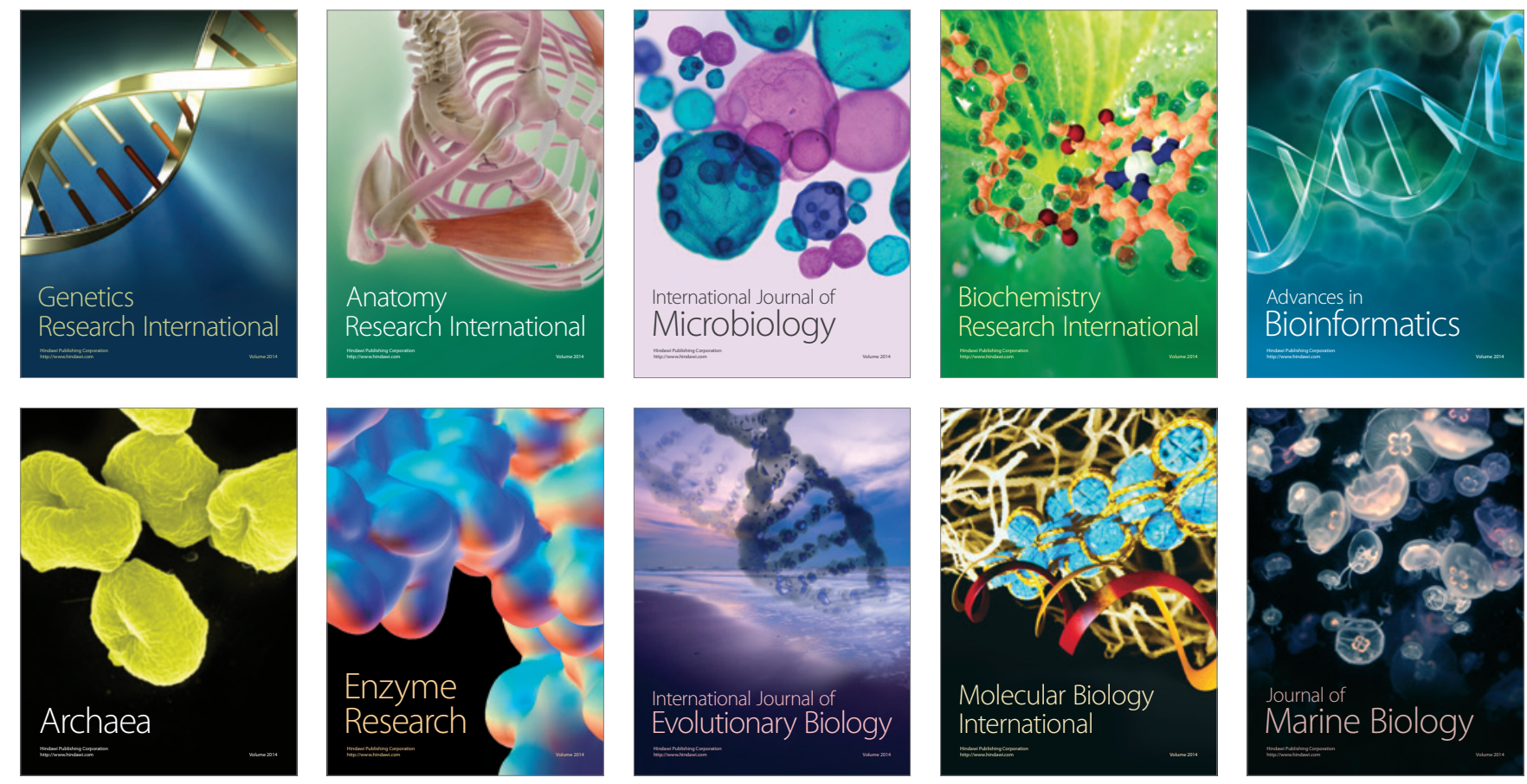